\title{
Estabelecimento de plantas herbáceas em solo com contaminação de metais pesados e inoculação de fungos micorrízicos arbusculares ${ }^{(1)}$
}

\author{
Marco Aurélio Carbone Carneiro(2), José Oswaldo Siqueira ${ }^{(3)}$ e Fátima Maria de Souza Moreira ${ }^{(3)}$
}

Resumo - Neste trabalho estudou-se o estabelecimento de plantas herbáceas em solo com contaminação de metais pesados (MP) e inoculação de fungos micorrízicos arbusculares (FMAs). O experimento foi realizado em bandejas, em esquema fatorial $5 \times 2$, sendo cinco proporções de solo contaminado com MP na ausência e presença de FMAs. Sementes de oito espécies de gramíneas e uma crucífera (mostarda-Brassica sp.) foram plantadas e cultivadas por 120 dias e avaliadas em dois cortes. No primeiro corte, as gramíneas foram severamente afetadas pela contaminação, e a mostarda foi pouco afetada, mostrando alta tolerância. No segundo corte, o efeito da contaminação foi negligível para as gramíneas, e a inoculação dos FMAs aumentou em $24 \%$ a matéria seca destas em relação ao controle sem inoculação. A inoculação teve também efeito positivo na matéria seca das raízes e na colonização micorrízica. Os teores de $\mathrm{Cd}, \mathrm{Zn}$ e $\mathrm{Pb}$ na parte aérea foram maiores na mostarda do que nas gramíneas em ambos os cortes. Apesar de a inoculação não ter efeito no crescimento das gramíneas do primeiro corte, as plantas com inoculação apresentaram maior acúmulo de $\mathrm{Zn}, \mathrm{Cd}$ e $\mathrm{Pb}$ no segundo corte. A maior tolerância da mostarda aos metais pesados permitiu seu crescimento e conseqüente acúmulo de $\mathrm{Zn}, \mathrm{Cd}$ e $\mathrm{Pb}$ do solo contaminado. A extração destes elementos do solo pode ter contribuído para o melhor desenvolvimento subseqüente das gramíneas, favorecendo o estabelecimento das plantas.

Termos para indexação: inoculação, etapas de desenvolvimento das plantas, degradação do solo, poluição do solo.

\section{Establishment of herbaceous plants in heavy metal contaminated soils inoculated with arbuscular mycorrhizal fungi}

\begin{abstract}
The establishment of herbaceous plants in soil contaminated by heavy metals (HM) and inoculated with arbuscular mycorrhizal fungi (AMF) was evaluated in the present study. The experiment was conducted in trays, in a $5 \times 2$ factorial, being five proportions of contaminated soil with or without inoculation with arbuscular mycorrhizal fungi (AMF). Seeds of eight grass species and a mustard (Brassica sp.) were planted and allowed to grow for 120 days under greenhouse conditions and assessed through two cuts. In the first cut grass species were severely affected by soil contamination, whereas the mustard was little affected, thus exhibiting high tolerance. In the second cut, the effect of soil contamination was negligible for the grasses, and inoculation with AMF increased dry matter yield by $24 \%$ over non-inoculated controls. Inoculation also had positive effects on root dry matter and colonization. Shoot concentrations of $\mathrm{Cd}, \mathrm{Zn}$ and $\mathrm{Pb}$ were higher in mustard in the first cut than in grasses in both cuts. Although inoculation had no effect on grass dry matter in the first cut, it enhanced accumulation of $\mathrm{Zn}, \mathrm{Cd}$ and $\mathrm{Pb}$ in these plants in the second cut. Higher tolerance of mustard to heavy metals allowed its growth and enhanced $\mathrm{Zn}, \mathrm{Cd}$ and $\mathrm{Pb}$ uptake from the contaminated soil. The extraction of these elements may have contributed for the enhanced subsequent development of the grasses and therefore facilitated plant establishment.
\end{abstract}

Index terms: inoculation methods, plant developmental stages, soil deterioration, soil pollution.

(1) Aceito para publicação em 20 de agosto de 2001.

Trabalho financiado pelo convênio Companhia Mineira de Metais/Faepe e Fapemig.

(2) Universidade Federal de Goiás, Campus Avançado de Jataí, Zona Rural, Br 364, km 192, Caixa Postal 03, CEP 75800-000 Jataí, GO. E-mail: mcarbone@jatai.ufg.br

(3) Universidade Federal de Lavras, Dep. de Ciência do Solo, Caixa Postal 37, CEP 37200-000 Lavras, MG Bolsista do CNPq. E-mail: siqueira@ufla.br, fmoreira@ufla.br

\section{Introdução}

Os metais pesados (MP), definidos como elementos com densidade relativa maior que $5 \mathrm{~g} \mathrm{~cm}^{-3}$, estão presentes em rochas e em concentrações elevadas, em áreas com adição de rejeitos industriais, biossólidos e alguns agroquímicos. Alguns desses elementos são essenciais para várias funções fisioló- 
gicas nos seres vivos, como $\mathrm{Fe}, \mathrm{Cu}, \mathrm{Zn}$ e $\mathrm{Mn}$, enquanto outros, como $\mathrm{Cd}, \mathrm{Pb}$ e $\mathrm{Hg}$, não têm funções biológicas conhecidas. Quando em excesso no solo, esses elementos podem inibir o crescimento das plantas e causar alterações nas comunidades vegetais (Baker et al., 1994), como também exercer efeitos adversos sobre os microrganismos do solo (Valsecchi et al., 1995), interferindo nas funções do ecossistema, com conseqüências ao meio ambiente e à saúde pública.

Grandes esforços têm sido feitos para integrar conhecimentos que facilitem a reabilitação de solos poluídos com metais pesados, e assim, possibilitar o retorno da funcionabilidade e estabilidade do ecossistema formado (Vangronsveld \& Cunningham, 1998). Para isto, procura-se amenizar o efeito da fitotoxicidade dos metais no solo, visando ao estabelecimento da vegetação. Estudos realizados em regiões temperadas com plantas tolerantes membros da família Poaceae (Agrostis tenus, Agrostis stolonifera e Festuca rubra) e Brassicaceae (Brassica rapus, Brassica juncea e Thlaspi spp.) evidenciam as oportunidades para a revegetação de solos contaminados com estas espécies (Salt et al., 1998). Entretanto, estudos como esses ainda não foram realizados no Brasil.

Raízes da maioria das plantas geralmente associam-se a fungos da ordem Glomales do Zigomicetes, formando simbioses mutualistas denominadas micorrizas arbusculares. Estas, mediante efeitos diversos, nutricionais e não-nutricionais, facilitam o crescimento vegetal, exercendo papel importante na revegetação de áreas degradadas (Miller \& Jastrow, 1992), inclusive nas áreas que apresentavam excesso de metais, onde as plantas com micorrizas são menos afetadas que as sem micorrizas (Leyval et al., 1997; Klauberg-Filho, 1999; Siqueira et al., 1999). As micorrizas reduzem a absorção de MP quando estes encontram-se em excesso, imobilizam temporariamente nas hifas os metais absorvidos do solo, diminuindo a translocação desses elementos para a parte aérea (Leyval et al., 1997), ou, ainda, interferem no desbalanço nutricional causado pelo metal tóxico, aumentando, por exemplo, a absorção de Fe (Siqueira et al., 1999).

Em programas de recuperação de áreas degradadas, uma das estratégias é a introdução de vegetação com o máximo de diversidade possível. Isto favorece a estabilização de plantas na área e a sucessão vegetal ao longo do processo de restauração (Vangronsveld \& Cunningham, 1998). No caso de solos contaminados com vários metais, a introdução de diferentes espécies vegetais é uma alternativa promissora. Diferenças na tolerância, no ciclo biológico, na rusticidade e na facilidade de estabelecimento em áreas desprovidas de vegetação são características que podem contribuir para o sucesso da estabilização de plantas em áreas com solos poluídos por metais pesados.

O objetivo deste trabalho foi avaliar a mistura de espécies de plantas e inoculação de fungos micorrízicos arbusculares (FMAs), no desenvolvimento vegetal em solo contaminado com metais pesados, visando a sua reabilitação.

\section{Material e Métodos}

O experimento foi realizado no período de 7/97 a 11/97 em casa de vegetação do Departamento de Ciência do Solo, na Universidade Federal de Lavras, MG, utilizando-se solo contaminado com metais pesados, coletado em área de deposição de rejeitos da industrialização de Zn da Companhia Mineira de Metais (CMM), localizada em Três Marias, MG. O solo apresentou os seguintes teores (extração Mehlich I) em mg kg-1: Zn, 12.000; Cd, 120; Pb, 800; $\mathrm{Cu}, 1.900$, além de outros metais em baixos teores.

O estudo constou de um fatorial 5 x 2 , com três repetições, em delineamento inteiramente casualizado, utilizando cinco misturas de solo contendo $0,7,5,15,30$ e 45\% (v/v) de solo contaminado com metais pesados, na ausência e presença de inoculação de FMAs. Como diluente nas misturas de solo, empregou-se um Latossolo Vermelho Ácrico típico, coletado próximo ao campus da Ufla, o qual recebeu, antes da mistura, calcário dolomítico para elevar a saturação de bases para 70\%. Após 15 dias de incubação, a mistura de solo recebeu $200 \mathrm{mg} \mathrm{kg}^{-1}$ de $\mathrm{P}$ (superfosfato simples) e $50 \mathrm{mg} \mathrm{kg}^{-1} \mathrm{de} \mathrm{N}$ (nitrato de amônio). À mistura de solos foi adicionado também $1 \mathrm{~kg}$ de vermicomposto, sendo novamente homogeneizado e acondicionado em bandejas de $0,60 \times 0,30 \times 0,10 \mathrm{~m}$ com capacidade de $11 \mathrm{~L}$. As características químicas dos substratos antes da inoculação dos FMAs e da semeadura encontram-se na Tabela 1. O substrato apresentou ainda textura argilosa, ausência de $\mathrm{Al}^{+3}$ e $40 \mathrm{~g} \mathrm{~kg}^{-1}$ de matéria orgânica.

$\mathrm{Na}$ inoculação dos FMAs, utilizaram-se $100 \mathrm{~mL}$ por bandeja de solo-inóculo, obtido de vaso de cultivo com braquiária (Brachiaria decumbens Stapf ), constando pe- 
daços de raízes, hifas e outros propágulos, apresentando, em média, 31 esporos $\mathrm{mL}^{-1}$. No inóculo, foram encontradas as espécies Acaulospora scrobiculata Trappe, Glomus occultum Nicolson \& Schenck, Glomus etunicatum Becker \& Gerdemann e Gigaspora margarita Becker \& Hall. Foram encontrados 15 esporos de fungos indígenas nãoidentificados por $50 \mathrm{~mL}$ de solo diluente. Para a contagem, os esporos foram extraídos pela técnica de peneiramento úmido (Gerdemann \& Nicolson, 1963) e contados em microscópio estereoscópio. Visando equilibrar a microbiota, os tratamentos sem inoculação receberam $100 \mathrm{~mL}$ de um filtrado do solo-inóculo ausente de propágulos de FMAs.

Nas bandejas, realizou-se a semeadura direta com mistura de nove espécies herbáceas, sendo oito gramíneas: Chloris gayana Kunt (capim-rhodes), Melinis minutiflora Beauv (capim-gordura), Rhynchelytrum repens (Wild) C.E. Hubb, Brachiaria brizantha Stapf (braquiária), Pennisetum americanum (milheto), Sorghum sudanensis (sorgo), Setaria anceps Schumach. Moss (capim-setária) e Andropogon gayanus Kunt (capim-andropógon) e a crucífera: Brassica sp. (mostarda não cultivada). Quanto às gramíneas, empregaram-se sementes fornecidas pelo Departamento de Zootecnia da Ufla, e as da crucífera foram coletadas em áreas de cultivo no campus da Ufla. Foram semeadas 20 sementes viáveis de cada espécie, por bandeja. As bandejas foram mantidas em casa de vegetação, com umidade do solo ajustada para $60 \%$ do volume total de poros, e assim mantidas durante a realização do experimento por meio de pesagens periódicas. Foram realizados dois cortes da parte aérea: o primeiro, aos 60 dias, e o segundo, aos 120 dias após a semeadura. Após o primeiro corte, realizou-se uma adubação de cobertura com $50 \mathrm{mg} \mathrm{kg}^{-1}$ de N (sulfato de amônio)

Tabela 1. Características químicas das misturas de solo diluente (Latossolo Vermelho Ácrico típico) com solo contaminado com metais pesados, antes da inoculação dos fungos micorrízicos arbusculares.

\begin{tabular}{lrrrrr}
\hline \multirow{2}{*}{ Característica } & \multicolumn{5}{c}{ Proporção de solo contaminado na mistura (\%) } \\
\cline { 2 - 6 } & 0 & 7,5 & 15 & 30 & 45 \\
\hline $\mathrm{pH}(\mathrm{em} \mathrm{água)}$ & 6,3 & 6,4 & 6,4 & 6,5 & 6,5 \\
$\mathrm{P}\left(\mathrm{mg} \mathrm{dm}^{-3}\right)$ & 54 & 69 & 84 & 93 & 78 \\
$\mathrm{~K}\left(\mathrm{mg} \mathrm{dm}^{-3}\right)$ & 172 & 200 & 246 & 234 & 206 \\
$\mathrm{Ca}\left(\mathrm{mmol}_{\mathrm{c}} \mathrm{dm}^{-3}\right)$ & 5,0 & 5,2 & 5,5 & 4,9 & 5,2 \\
$\mathrm{Mg}\left(\mathrm{mmol}_{\mathrm{c} \mathrm{dm}}{ }^{-3}\right)$ & 2,9 & 2,9 & 3,2 & 3,7 & 3,2 \\
$\mathrm{H}+\mathrm{Al}\left(\mathrm{mmol}_{\mathrm{c}} \mathrm{dm}^{-3}\right)$ & 2,3 & 2,3 & 2,3 & 2,3 & 2,3 \\
$\mathrm{~S}\left(\mathrm{mmol}_{\mathrm{c} \mathrm{dm}}{ }^{-3}\right)$ & 8,3 & 8,6 & 9,3 & 9,2 & 8,9 \\
$\mathrm{~V}(\%)$ & 78 & 79 & 80 & 80 & 80 \\
$\mathrm{Cu}\left(\mathrm{mg} \mathrm{dm}^{-3}\right)$ & 1,8 & 132 & 248 & 530 & 658 \\
$\mathrm{Zn}^{(1)}\left(\mathrm{mg} \mathrm{dm}^{-3}\right)$ & 2 & 273 & 456 & 896 & 1.274 \\
$\mathrm{Cd}^{(1)}\left(\mathrm{mg} \mathrm{dm}^{-3}\right)$ & $<1$ & 9 & 25 & 49 & 79 \\
$\mathrm{~Pb}^{(1)}\left(\mathrm{mg} \mathrm{dm}^{-3}\right)$ & $<1$ & 32 & 74 & 136 & 195 \\
\hline${ }_{(1)}$ Extraídos por Mehlich-1. & & & &
\end{tabular}

${ }^{(1)}$ Extraídos por Mehlich-1
No primeiro corte, foi avaliada a matéria seca da parte aérea das gramíneas e da mostarda, enquanto no segundo corte, somente as gramíneas apresentaram crescimento para avaliação da parte aérea. A parte aérea dos dois cortes foi lavada e secada em estufa com circulação forçada de ar a $70^{\circ} \mathrm{C}$, até peso constante, obtendo-se a matéria seca da parte aérea (MSPA) de cada corte. No último corte, as raízes das gramíneas foram separadas do solo, por meio de peneiramento, e lavadas, retirando-se $1 \mathrm{~g}$ de raízes finas para avaliação de colonização após clarificação e coloração, conforme Kormanik \& McGraw (1982). As avaliações foram feitas em placas quadriculadas (Giovannetti $\&$ Mosse, 1980). O restante das raízes foi secada em estufa, para a obtenção do peso da matéria seca. Após a secagem, os materiais dos dois cortes foram moídos em moinho tipo Willey, para análises dos teores de nutrientes e metais pesados (Hunter, 1975). Os teores de P foram determinados por colorimetria; os de $\mathrm{K}$, por fotometria de chama; os teores de $\mathrm{Ca}, \mathrm{Mg}, \mathrm{Cu}, \mathrm{Fe}$ e $\mathrm{Zn}$, por espectrofotometria de absorção atômica (Sarruge \& Haag, 1974) e os de $\mathrm{Cd} \mathrm{e} \mathrm{Pb}$, por espectrometria atômica de emissão de plasma (Zarosky \& Burau, 1977).

As quantidades de nutrientes acumuladas na parte aérea foram calculadas com base no peso da matéria seca da parte aérea e no teor de cada nutriente, e o total de elementos absorvidos foi calculado com base nos teores e matéria seca, em cada corte. Para a translocação, somouse o total do elemento acumulado na parte aérea total, ou seja, dos dois cortes (mostarda 1o corte + gramíneas 1o corte + gramíneas 2 o corte), dividido pelo total acumulado na planta (parte aérea total + raízes).

Os resultados obtidos foram submetidos a análises de variância, correlações de Pearson, e teste de Tukey a 5\% de probabilidade na comparação das médias. As regressões significativas, pelo teste $\mathrm{F}$, foram obtidas pelo programa Table Curve (Jandel Scientific Corporation).

\section{Resultados e Discussão}

Quanto à matéria seca, no primeiro corte da parte aérea (MSPA), houve efeito $(\mathrm{P} \leq 0,05)$ da contaminação do solo com metais pesados (MP) e da inoculação dos FMAs na mostarda, sem, entretanto, ter havido interação entre esses fatores. Nas gramíneas, houve efeito apenas da contaminação do solo com MP (Figura 1). No primeiro corte, a adição de pequena quantidade de solo contaminado na mistura estimulou a produção de MSPA da mostarda, atingindo-se o máximo com $18 \%$ de solo contaminado, reduzindo-se 
nas proporções de solo contaminado (PSC) mais elevadas. Comportamento contrário foi verificado nas gramíneas, que se mostraram muito sensíveis à contaminação do solo com MP, e sofreram grande inibição. A mostarda, apesar de ter seu crescimento reduzido em $35 \%$ na PSC mais elevada, foi menos afetada do que as gramíneas, que sofreram redução de até $88 \%$ no primeiro corte. Um aspecto interessante é que, apesar de não serem quantificadas separadamente, as espécies braquiária, setária e andropógon foram as que mais contribuíram na produção de matéria seca total da parte aérea no primeiro corte, porém, certas espécies, como o capim-gordura e $R$. repens, nem mesmo germinaram nas maiores PSC.

A produção de MSPA da mostarda diferiu significativamente, pois no tratamento inoculado foi de 43,2 g por bandeja, e de 33,9 g por bandeja no nãoinoculado. Esse efeito deve ser resultado de algum mecanismo indireto dos FMAs, pois as crucíferas, em geral, incluindo a mostarda, não são micotróficas (Smith \& Read, 1997), e, de fato, nenhum sinal de micorrização foi encontrado nas raízes do ecótipo estudado paralelamente. É de certo modo estranha a ausência de efeito da inoculação nas gramíneas no primeiro corte. Isto pode estar relacionado a três fatores: primeiro, as concentrações de MP terão inibido o crescimento das plantas a ponto de comprometer o funcionamento da simbiose. Isto pode ser observado pela MSPA na menor PSC $(0 \%)$, situação esta em que não se verifica diferença significativa

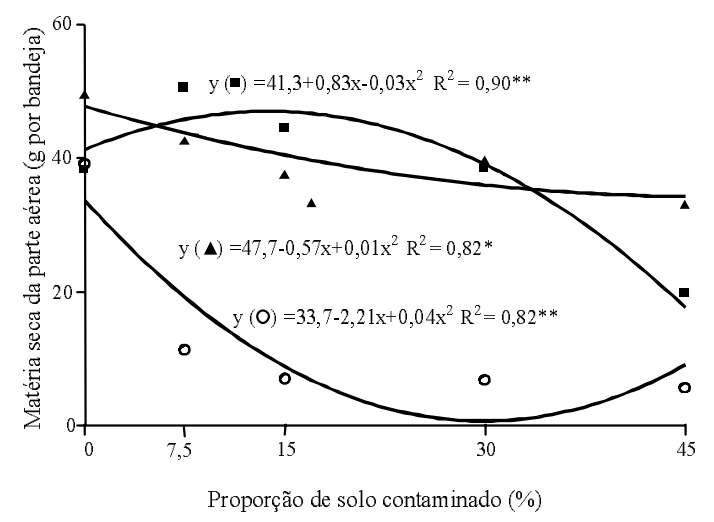

Figura 1. Produção de matéria seca da parte aérea da mostarda (ロ) e das gramíneas no primeiro (O) e no segundo corte $(\mathbf{\Lambda})$, em razão das misturas de solo contendo proporções de solo contaminado com metais pesados. entre a mostarda e as gramíneas. Em segundo lugar, o fato de que aos 60 dias após a semeadura (data do primeiro corte), em face dos metais que retardam a colonização, os FMAs não haviam, ainda, colonizado efetivamente as raízes. Klauberg-Filho (1999), trabalhando com o mesmo solo contaminado, observou que a colonização micorrízica de plantas de braquiárias e de colonião foi inferior no solo contaminado, em relação ao solo sem contaminação, até 85 dias após a inoculação. Portanto, a contaminação retarda a colonização, tendo efeitos imediatos no crescimento e estabelecimento daquelas plantas neste solo, e, finalmente, a mostarda produz substâncias como glucosinolatos, que têm ação biocida (Sarwar \& Kirkegaard, 1998), dificultando, assim, o desenvolvimento da colonização e seu efeito no crescimento das gramíneas.

No segundo corte, verificou-se uma tendência de a matéria seca da parte aérea das gramíneas ser maior em relação ao primeiro corte, e menos influenciada pela contaminação (Figura 1). A inoculação dos FMAs proporcionou aumentos de $18 \%$ na MSPA, diferindo estatisticamente $(\mathrm{P} \leq 0,05)$. Resultado semelhante foi encontrado por Hetrick et al. (1994), que estudaram a inoculação dos FMAs em outras gramíneas em solos com altos teores de $\mathrm{Cd}, \mathrm{Zn}$ e $\mathrm{Pb}$.

A matéria seca de raízes (MSR) coletada somente no segundo corte foi influenciada pelos fatores estudados e pela interação destes (Figura 2). A elevação da contaminação do solo com MP proporcionou redução na MSR em todas as PSC, enquanto a inoculação dos FMAs aumentou a biomassa radicular em torno de $35 \%$ em relação ao tratamento não-inoculado. Efeitos semelhantes da colonização micorrízica (CM) foram encontrados em solo com inoculação, em que os valores foram, em média, 39\% maiores do que em solo sem inoculação (Figura 2). Esses resultados também foram observados em outros estudos com o mesmo solo (Klauberg-Filho, 1999; Siqueira et al., 1999) e em condições e hospedeiros diferentes (Hetrick et al., 1994; Shetty et al., 1995; Vidal et al., 1996). Nos solos sem inoculação, provavelmente em virtude da baixa densidade de esporos de FMAs (15 esporos por $50 \mathrm{~mL}$ ), verificaram-se menores CM e MSR, diferindo dos que receberam FMAs, confirmando o efeito benéfico da inoculação desses fungos no solo estudado. O excesso de MP pode estar inibindo ou retardando a germi- 
nação dos esporos de FMAs, o que afetaria diretamente a colonização radicular (Tommerup, 1983). Portanto, a inibição da colonização micorrízica pelo excesso de MP pode retardar o crescimento e o estabelecimento de plantas em áreas contaminadas por estes metais.

Os teores e acúmulo de $\mathrm{Cd}, \mathrm{Pb}$ e $\mathrm{Zn}$ na MSPA foram influenciados pela contaminação, e não houve efeito da inoculação dos FMAs (Figura 3). Os teores de $\mathrm{Cd}$ aumentaram com a elevação na contaminação, e houve pequenas diferenças entre a mostarda e
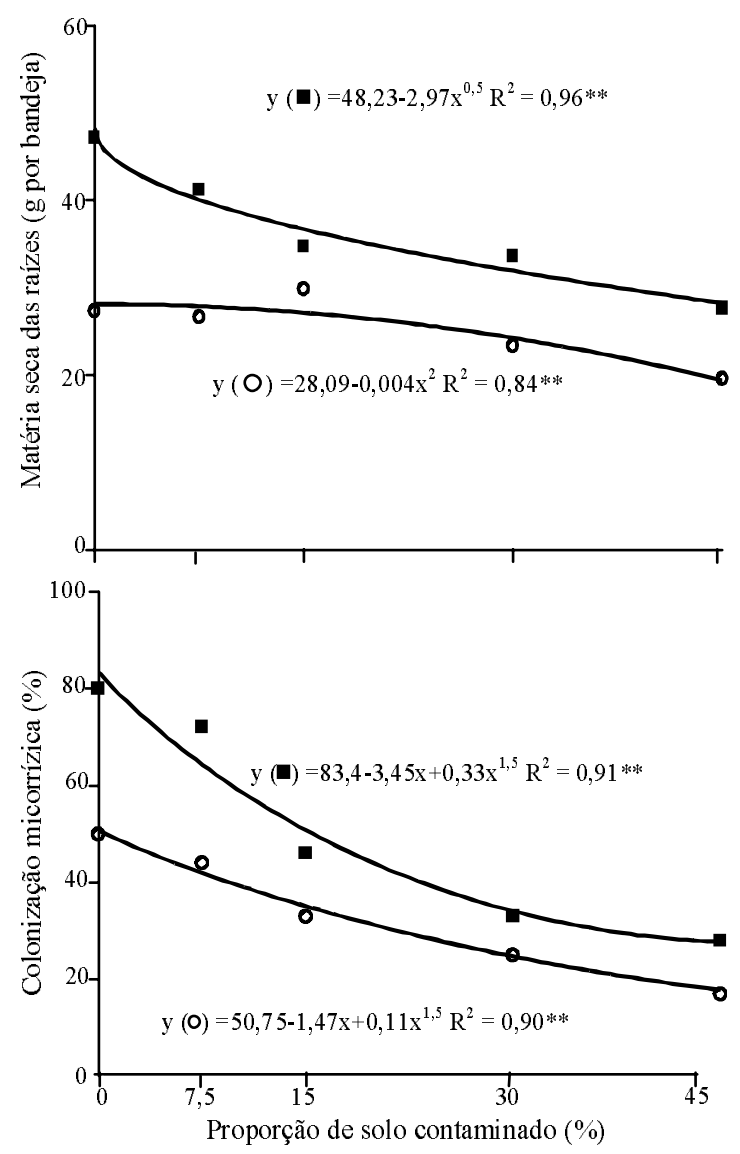

- Com inoculação

O Sem inoculação

Figura 2. Produção de matéria seca das raízes e colonização micorrízica das gramíneas no segundo corte, em razão das mistura de solo contendo proporções de solo contaminado com metais pesados, e da inoculação de FMAs. as gramíneas no primeiro e segundo cortes. As gramíneas apresentaram menores quantidades acumuladas de $\mathrm{Cd}$ no primeiro corte, enquanto a mostarda e as gramíneas do segundo corte acumularam quantidades mais elevadas deste elemento, reflexo da maior quantidade de matéria seca da parte aérea. A mostarda apresentou teores mais elevados de $\mathrm{Zn}$ que as gramíneas, em ambos os cortes; estes cresceram com o aumento da contaminação. O Zn acumulado seguiu a produção de matéria seca: foi maior na mostarda, seguido pelas gramíneas do segundo corte. Quanto ao $\mathrm{Pb}$, também verificaram-se teores mais elevados na mostarda, seguido pelas gramíneas no primeiro corte, também evidenciados nas quantidades acumuladas desse elemento.

A contaminação influenciou negativamente o teor de $\mathrm{P}$ na parte aérea das plantas (primeiro corte: mostarda, $\mathrm{Y}=4,21-0,038 \mathrm{X} ; \mathrm{R}^{2}=0,97 * *$; gramíneas, $\mathrm{Y}=$ $1,98-0,017 \mathrm{X} ; \mathrm{R}^{2}=0,99^{* *}$, e nas gramíneas do segundo corte, $\mathrm{Y}=2,82-0,047 \mathrm{X} ; \mathrm{R}^{2}=0,90^{* *}$, sendo $\mathrm{Y}$ a concentração de $\mathrm{P}$, e $\mathrm{X}$ a proporção de solo contaminado). Na maior contaminação (PSC 45\%) observou-se redução de $36 \%$ na concentração de $\mathrm{P}$ na parte aérea da mostarda e das gramíneas do primeiro corte, em relação ao controle (PSC 0\%). Nas gramíneas do segundo corte, quando houve efeito evidente da inoculação dos FMAs, plantas com inoculação apresentaram menor redução (53\%) nos teores de $\mathrm{P}$ do que as sem inoculação (83\%). Isto confirma o forte envolvimento dos FMAs na nutrição fosfática em condições de estresse nutricional (Siqueira \& Saggin-Junior, 1995).

A inoculação influenciou os teores dos nutrientes e do $\mathrm{Cd}$ e $\mathrm{Pb}$ nas plantas (Tabela 2). Não houve efeito na concentração de $\mathrm{Cd}$ na mostarda e nas gramíneas dos dois cortes, exceto nas raízes, onde plantas com inoculação apresentaram maior concentração de cádmio. A concentração de $\mathrm{P}, \mathrm{Zn}$ e Fe na mostarda com inoculação foi em torno de duas vezes superior à encontrada nas gramíneas em ambos os cortes, independentemente do tratamento com FMAs. Esses resultados indicam que as gramíneas foram severamente afetadas pela contaminação no primeiro corte, e que, possivelmente, a menor absorção de $\mathrm{P}$ ( $1,6 \mathrm{~g} \mathrm{~kg} \mathrm{~g}^{-1}$ nas gramíneas e $3,5 \mathrm{~g} \mathrm{~kg}^{-1}$ na mostarda), aliada à ausência de efeito da inoculação, contribuíram para o menor crescimento destas espécies. 
Como relatado na literatura para crucíferas em geral (Raskin et al., 1997; Salt et al., 1998), no presente estudo a mostarda também apresentou teores mais elevados de $\mathrm{P}$ e Fe sendo mais tolerante aos metais pesados que as gramíneas. Considerando o antagonismo do $\mathrm{Zn}, \mathrm{Pb}$ e $\mathrm{Cd}$ na absorção do $\mathrm{P}$ e Fe (Kabata-Pendias \& Pendias, 1984), isto pode ter contribuído para a maior tolerância desta espécie aos metais pesados. Por ser mais tolerante, a mostarda foi capaz de crescer mais, e assim, retirar maior quan- tidade dos metais tóxicos do solo, reduzindo a disponibilidade destes e facilitando o crescimento subsequiente das gramíneas. A concentração de $\mathrm{Cd}$ nas raízes foi maior em plantas com inoculação e cerca de três vezes superior em relação à parte aérea, tanto na mostarda quanto nas gramíneas, em ambos os cortes, evidenciando, assim, a menor translocação desses metais em plantas com inoculação, como já mencionado em outros estudos (Leyval et al., 1997; Klauberg-Filho, 1999).
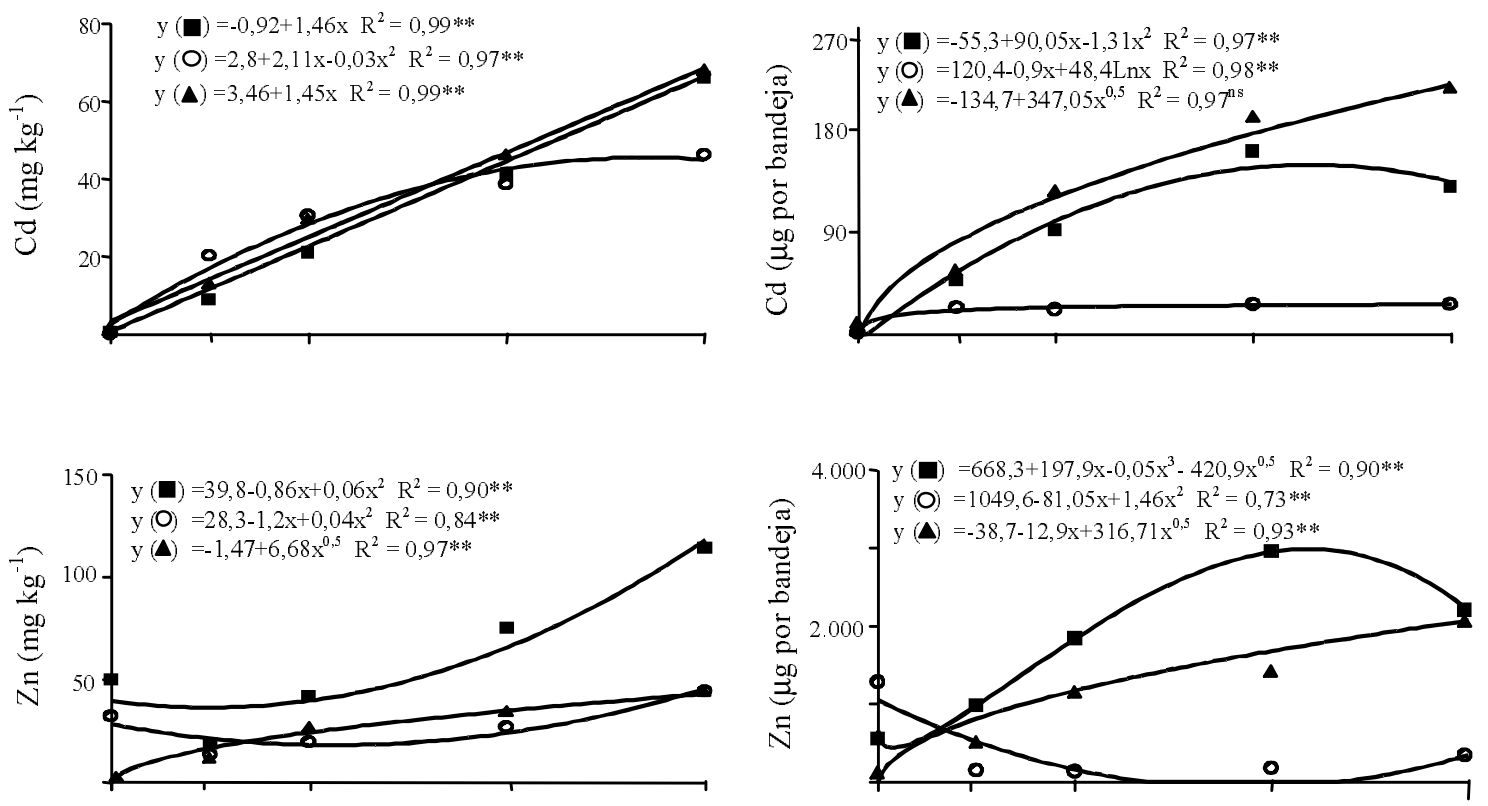

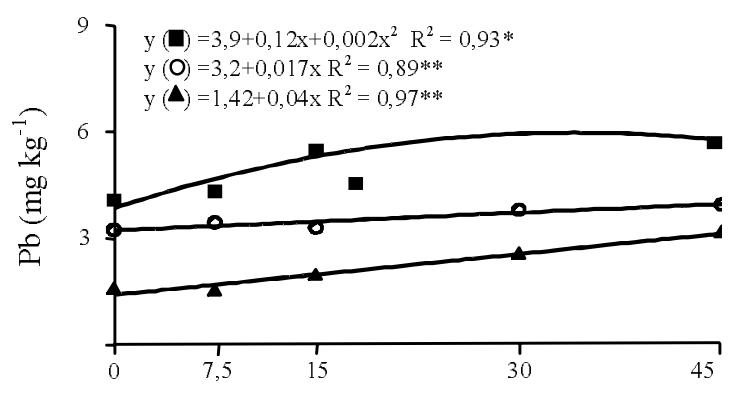

Proporção de solo contaminado (\%)

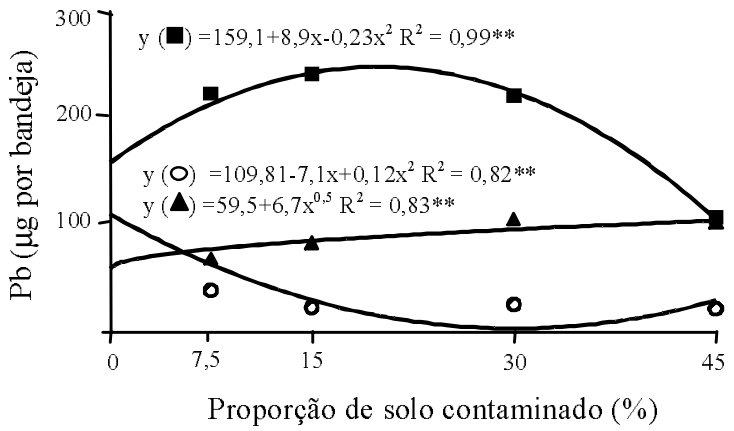

Figura 3. Concentração e acúmulo de $\mathrm{Cd}, \mathrm{Zn}$ e $\mathrm{Pb}$ na matéria seca da parte aérea da mostarda (®) e das gramíneas no primeiro corte (O) e das gramíneas no segundo corte (ム), em razão das mistura de solo contendo diferentes proporções de solo contaminado com metais pesados. 
Houve correlação positiva significativa entre as concentrações de $\mathrm{Zn}$ e $\mathrm{Cd}$ no solo e os teores destes elementos na parte aérea das plantas, em ambos os cortes (Tabela 3). A correlação entre os teores de $\mathrm{P}$ na parte aérea das plantas e os teores de $\mathrm{Zn}, \mathrm{Cd} \mathrm{e} \mathrm{Pb}$ no solo foi alta, consistente e inversa, fato este não observado nos teores nas raízes das plantas com inoculação. Esses resultados indicam possível efeito adverso do excesso de metais no solo na absorção/ translocação de $\mathrm{P}$ pelas plantas e também o envolvimento das FMAs nestas interações.

Plantas com inoculação acumularam maiores quantidades de $\mathrm{Zn}$, Cd e $\mathrm{Pb}$, porém translocaram menores quantidades de $\mathrm{Cd}$ e $\mathrm{Pb}$ para a parte aérea, conforme mostram os valores do índice de translocação destes elementos (em média 35\%), significativamente $(\mathrm{P} \leq 0,05)$ menores nas plantas com inoculação. Quanto ao Zn, este índice foi elevado (68\%) e sem efeito da inoculação. O Cd e o Pb provavelmente foram mais imobilizados nas raízes e hifas fúngicas, restringindo sua translocação, como suge- rido em vários estudos (Dueck et al., 1986; Shetty et al., 1995). Vangronsveld \& Cunningham (1998) consideram que a retenção de metais nas raízes é um mecanismo importante de tolerância ao excesso de metais pesados, fenômeno, este, favorecido pelos FMAs, que restringem a transferência dos metais para a planta hospedeira, dada a forte afinidade entre a parede fúngica e os metais (Leyval et al., 1997).

A capacidade da planta em concentrar metais pesados, principalmente $\mathrm{Cd}, \mathrm{Zn}$ e $\mathrm{Pb}$, é um fator importante para o sucesso da fitorremediação (Accioly \& Siqueira, 2000). No presente trabalho, a mostarda mostrou-se promissora para esta finalidade, corroborando outros estudos com brássicas de clima temperado (Raskin et al., 1997). Segundo Salt et al. (1995), a Brassica juncea é capaz de acumular $\mathrm{Pb}$ por meio da produção de quelantes nas suas raízes, enquanto o acúmulo de Cd está relacionado à taxa de transpiração e de absorção pelas raízes.

Tabela 2. Efeito da presença (+) e ausência (-) de fungos micorrízicos arbusculares (FMAs) no teor de macronutrientes $\left(\mathrm{mg} \mathrm{kg}^{-1}\right)$, de micronutrientes $\left(\mu \mathrm{g} \mathrm{kg}^{-1}\right)$ e de $\mathrm{Cd} \mathrm{e} \mathrm{Pb}\left(\mu \mathrm{g} \mathrm{kg}^{-1}\right)$ na matéria seca da parte aérea (1ㅇ e 2 o corte) e das raízes $\left(2^{\circ}\right.$ corte $)$ das diferentes espécies herbáceas ${ }^{(1)}$.

\begin{tabular}{|c|c|c|c|c|}
\hline Nutriente & FMAs $(+)$ & FMAs (-) & FMAs $(+)$ & FMAs (-) \\
\hline & \multicolumn{2}{|c|}{ Mostarda $1^{\circ}$ corte } & \multicolumn{2}{|c|}{ Gramíneas $1^{\circ}$ corte } \\
\hline $\mathrm{P}$ & $3,5 \mathrm{a}$ & $3,5 \mathrm{a}$ & $1,6 a$ & $1,7 \mathrm{a}$ \\
\hline S & $2,9 a$ & $2,6 \mathrm{~b}$ & $3,0 \mathrm{~b}$ & $3,3 a$ \\
\hline $\mathrm{K}$ & $23,5 b$ & $24,8 \mathbf{a}$ & $21,3 b$ & $23,0 \mathbf{a}$ \\
\hline $\mathrm{Ca}$ & $26,1 b$ & $28,0 \mathrm{a}$ & $5,0 \mathrm{~b}$ & $5,4 \mathrm{a}$ \\
\hline $\mathrm{Mg}$ & $7,2 \mathrm{a}$ & $7,4 a$ & $8,1 b$ & $9,4 a$ \\
\hline $\mathrm{Zn}$ & $60,2 a$ & $60,2 a$ & $25,1 \mathrm{~b}$ & $30,1 \mathrm{a}$ \\
\hline $\mathrm{Cu}$ & $15,3 \mathrm{a}$ & $15,5 \mathbf{a}$ & $12,5 \mathbf{a}$ & $12,4 a$ \\
\hline $\mathrm{Fe}$ & $380 a$ & $563 a$ & $221 \mathrm{a}$ & $193 a$ \\
\hline Mn & $37,9 \mathbf{a}$ & $38,9 \mathbf{a}$ & $47,9 \mathbf{a}$ & $50,3 \mathbf{a}$ \\
\hline $\mathrm{Cd}$ & $27,6 a$ & $27,4 a$ & $27,0 \mathbf{a}$ & $27,2 \mathbf{a}$ \\
\hline \multirow[t]{2}{*}{$\mathrm{Pb}$} & $4,2 \mathrm{~b}$ & $6,0 \mathbf{a}$ & $3,1 \mathrm{~b}$ & $4,1 \mathrm{a}$ \\
\hline & \multicolumn{2}{|c|}{ Gramíneas $2^{\circ}$ corte } & \multicolumn{2}{|c|}{ Gramíneas-raízes } \\
\hline $\mathrm{P}$ & $1,9 \mathrm{a}$ & $2,0 \mathbf{a}$ & $1,1 \mathrm{a}$ & $0,8 \mathrm{~b}$ \\
\hline S & $5,3 a$ & $5,5 \mathrm{a}$ & $9,5 b$ & $10,6 \mathbf{a}$ \\
\hline $\mathrm{K}$ & $19,1 \mathbf{a}$ & $16,3 b$ & $19,1 b$ & $21,5 \mathrm{a}$ \\
\hline $\mathrm{Ca}$ & $40,3 b$ & $43,9 \mathbf{a}$ & $22,4 b$ & $26,1 \mathrm{a}$ \\
\hline $\mathrm{Mg}$ & $1,8 \mathrm{~b}$ & $2,0 \mathbf{a}$ & $6,9 \mathbf{a}$ & $6,3 b$ \\
\hline $\mathrm{Zn}$ & $24,6 \mathbf{a}$ & $23,5 \mathrm{a}$ & $65,3 a$ & $60,7 a$ \\
\hline $\mathrm{Cu}$ & $6,8 \mathrm{a}$ & $6,6 a$ & $169 \mathrm{a}$ & $169 a$ \\
\hline $\mathrm{Fe}$ & $338 a$ & $291 \mathrm{a}$ & $245 a$ & $227 \mathrm{a}$ \\
\hline Mn & $46,2 a$ & $43,5 \mathbf{a}$ & $68,8 \mathrm{a}$ & $86,0 \mathbf{a}$ \\
\hline $\mathrm{Cd}$ & $32,1 \mathrm{a}$ & $31,4 a$ & $96,1 \mathrm{a}$ & $81,1 \mathrm{~b}$ \\
\hline $\mathrm{Pb}$ & $2,2 a$ & $2,1 \mathrm{a}$ & $28,2 \mathrm{a}$ & $29,5 \mathbf{a}$ \\
\hline
\end{tabular}

${ }^{(1)}$ Médias seguidas pela mesma letra, na linha, dentro de cada grupo de espécies, não diferem significativamente entre si pelo teste de Tukey a 5\%. 
Tabela 3. Correlação de Pearson de concentrações de $\mathrm{Zn}, \mathrm{Cd}$ e $\mathrm{Pb}$ no solo com os teores de $\mathrm{P}, \mathrm{Zn}, \mathrm{Cd}, \mathrm{Pb}$ e Cu na parte aérea da mostarda e de gramíneas nos dois cortes e nas raízes de gramíneas no segundo corte.

\begin{tabular}{|c|c|c|c|c|c|}
\hline \multirow{2}{*}{$\begin{array}{l}\text { Metais } \\
\text { pesados }\end{array}$} & \multicolumn{5}{|c|}{ Teor na planta } \\
\hline & $\mathrm{P}$ & $\mathrm{Zn}$ & $\mathrm{Cd}$ & $\mathrm{Pb}$ & $\mathrm{Cu}$ \\
\hline & \multicolumn{5}{|c|}{ Mostarda $1^{\circ}$ corte - Inoculado } \\
\hline $\mathrm{Zn}$ & $-0,83 * *$ & $0,94 * *$ & $0,89 * *$ & $0,51^{\mathrm{ns}}$ & $0,84^{* *}$ \\
\hline $\mathrm{Cd}$ & $-0,85 * *$ & $0,95 * *$ & $0,91 * *$ & $0,43^{\mathrm{ns}}$ & $0,86^{* *}$ \\
\hline $\mathrm{Pb}$ & $-0,86 * *$ & $0,94 * *$ & $0,92 * *$ & $0,38^{\text {ns }}$ & $0,87 * *$ \\
\hline \multicolumn{6}{|c|}{ Mostarda $1^{\circ}$ corte - Não-inoculado } \\
\hline $7 n$ & $-0,83 * *$ & $0,91 * *$ & $0,98 * *$ & $0,55^{*}$ & $0,86 * *$ \\
\hline $\mathrm{Cd}$ & $-0,85 * *$ & $0,89 * *$ & $0,98 * *$ & $0,55^{*}$ & $0,89 * *$ \\
\hline $\mathrm{Pb}$ & $-0,84 * *$ & $0,88 * *$ & $0,99 * *$ & $0,58^{*}$ & $0,88 * *$ \\
\hline \multicolumn{6}{|c|}{ Gramineas $1^{\circ}$ corte - Inoculado } \\
\hline $\mathrm{Zn}$ & $-0,94 * *$ & $0,67 * *$ & $0,86 * *$ & $0,51 *$ & $0,84 * *$ \\
\hline $\mathrm{Cd}$ & $-0,91 * *$ & $0,59 *$ & $0,89 * *$ & $0,50 *$ & $0,85 * *$ \\
\hline $\mathrm{Pb}$ & $-0,93 * *$ & $0,61 *$ & $0,90 * *$ & $0,54 *$ & $0,87 * *$ \\
\hline \multicolumn{6}{|c|}{ Gramineas $1^{\circ}$ corte - Não-inoculado } \\
\hline $7 \mathbf{n}$ & $-0,89 * *$ & $0,87 * *$ & $0,97 * *$ & $0,57 *$ & $0,87 * *$ \\
\hline $\mathrm{Cd}$ & $-0,89 * *$ & $0,80 * *$ & $0,96 * *$ & $0,58 *$ & $0,89 * *$ \\
\hline $\mathrm{Pb}$ & $-0,90 * *$ & $0,82 * *$ & $0,97 * *$ & $0,55 *$ & $0,87 * *$ \\
\hline \multicolumn{6}{|c|}{ Gramineas $2^{\circ}$ corte - Inoculado } \\
\hline $\mathrm{Zn}$ & $-0,79 * *$ & $0,83 * *$ & $0,85 * *$ & $0,68 *$ & $0,81 * *$ \\
\hline $\mathrm{Cd}$ & $-0,76 * *$ & $0,85 * *$ & $0,87 * *$ & $0,70 * *$ & $0,80 * *$ \\
\hline $\mathrm{Pb}$ & $-0,76 * *$ & $0,84 * *$ & $0,86 * *$ & $0,68 * *$ & $0,81 * *$ \\
\hline \multicolumn{6}{|c|}{ Gramineas $2^{\circ}$ corte - Não-inoculado } \\
\hline $\mathrm{Zn}$ & $-0,97 * *$ & $0,90 * *$ & $0,93 * *$ & $0,91 * *$ & $0,85^{* *}$ \\
\hline $\mathrm{Cd}$ & $-0,97 * *$ & $0,88 * *$ & $0,91 * *$ & $0,87 * *$ & $0,80 * *$ \\
\hline $\mathrm{Pb}$ & $-0,98 * *$ & $0,91 * *$ & $0,93 * *$ & $0,90 * *$ & $0,84 * *$ \\
\hline \multicolumn{6}{|c|}{ Raízes de gramíneas $2^{\circ}$ corte - Inoculado } \\
\hline $\mathrm{Zn}$ & $-0,43^{\text {ns }}$ & $0,98 * *$ & $0,98 * *$ & $0,91 * *$ & $0,95 * *$ \\
\hline $\mathrm{Cd}$ & $-0,38^{\text {ns }}$ & $0,99 * *$ & $0,99 * *$ & $0,91 * *$ & $0,96^{* *}$ \\
\hline $\mathrm{Pb}$ & $-0,39^{\mathrm{ns}}$ & $0,99 * *$ & $0,99 * *$ & $0,91 * *$ & $0,96 * *$ \\
\hline \multicolumn{6}{|c|}{ Raízes de gramíneas $2^{\circ}$ corte - Não-inoculado } \\
\hline $\mathrm{Zn}$ & $-0,77 * *$ & $0,93 * *$ & $0,95 * *$ & $0,89 * *$ & $0,90 * *$ \\
\hline $\mathrm{Cd}$ & $-0,80 * *$ & $0,90 * *$ & $0,93 * *$ & $0,86 * *$ & $0,90 * *$ \\
\hline $\mathrm{Pb}$ & $-0,79 * *$ & $0,94 * *$ & $0,95 * *$ & $0,89 * *$ & $0,92 * *$ \\
\hline
\end{tabular}

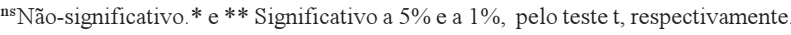

Considerando-se a maior contaminação estudada e a quantidade de metais presentes neste solo, bem como a expectativa de extração destes pelas plantas, estima-se que a mostarda retirou do solo cerca de 9\% do $\mathrm{Zn}$ e $\mathrm{Cd}$, capacidade, esta, elevada, quando comparada com espécies biorremediadoras, como a Brassica napus, que retira, em cada cultivo, apenas $3 \%$ do total de $\mathrm{Zn}$ no solo contaminado, por cada cultivo (Baker et al., 1994). Apesar de representar pequena quantidade de metal extraído, esta pode ter sido suficiente para favorecer o crescimento das gramíneas após o primeiro corte. Assim, a semeadura de mistura de espécies vegetais contendo mostarda tolerante, e a inoculação de FMAs, apresenta grande potencial para fitoestabilização de solos contaminados por metais pesados.

\section{Conclusões}

1. A mostarda é pouco afetada pela contaminação do solo com metais pesados, e por isso, acumula maior quantidade de $\mathrm{Zn}, \mathrm{Cd}$ e $\mathrm{Pb}$ extraídos do solo, o que parece favorecer o crescimento subseqüente de gramíneas em co-semeadura.

2. A inoculação de fungos micorrízicos arbusculares favorece o crescimento e reduz a translocação de $\mathrm{Cd}$ e $\mathrm{Pb}$ das raízes para a parte aérea das gramíneas, após co-semeadura com mostarda.

3. A semeadura conjunta de gramíneas e mostarda e a inoculação de FMAs favorecem o estabelecimento das plantas em misturas de solo contaminado com metais pesados; são, portanto, práticas pro- 
missoras para o estabelecimento de plantas em áreas degradadas pelo excesso de metais pesados.

\section{Referências}

ACCIOLY, A. M. A.; SIQUEIRA, J. O. Contaminação química e biorremediação do solo. In: NOVAES, R. F.; ALVAREZ, V. H. V.; SCHAEFER, C. E. G. R. (Ed.). Tópicos em Ciência do Solo. Viçosa, MG: Sociedade Brasileira de Ciência do Solo, 2000. p. 299-352.

BAKER, A. J. M.; McGRATH, S. P.; SODOLI, C. M. D.; REEVES, R. D. The possibility of in situ heavy metal decontamination of polluted soils using crops of metalaccumulating plants. Resources, Conservation and Recycling, Amsterdam, v. 11, p. 41-49, 1994.

DUECK, T. A.; VISSER, P.; ERNST, W. H. O.; SCHAT, H. Vesicular-arbuscular mycorrhizae decrease zinc toxicity to grasses growing in zinc-polluted soil. Soil Biology $\boldsymbol{\&}$ Biochemistry, Oxford, v. 18, p. 331-333, 1986

GERDEMANN, J. W.; NICOLSON, T. H. Spores of mycorrhizal endogone species extracted from soil by wit sieving and decanting. Transactions of the British Mycological Society, Cambridge, Inglaterra, v. 46, p. 235244, 1963

GIOVANNETTI, M.; MOSSE, B. An evaluation of techniques to measure vesicular-arbuscular mycorrhizal infection in roots. New Phytologist, Cambridge, Inglaterra, v. 84, p. 484-500, 1980

HETRICK, B. A. D.; WILSON, G. W. T.; FIGGE, D. A. H. The influence of mycorrhizal symbiosis and fertilizer amendments on establishment of vegetation in heavy metal mine spoil. Environmental Pollution, Oxford, v. 86, p. 171-179, 1994.

HUNTER, A. H. Laboratory analysis of vegetal tissues samples. Raleigh: North Carolina University, 1975. 5 p.

KABATA-PENDIAS, A.; PENDIAS, H. Trace elements in soils and plants. Boca Raton: CRC, 1984. 315 p.

KLAUBERG-FILHO, O. Ecologia e atividade de fungos micorrízicos arbusculares em solo poluído com metais pesados. Lavras: Ufla, 1999. 161 p. Tese de Doutorado.

KORMANIK, P. P.; McGRAW, A. C. Quantification of vesicular-arbuscular mycorrhizal in plant roots. In: SCHENCK, N. C. (Ed.). Methods and principles of mycorrhizal research. St. Paul: American Phytopathological Society, 1982. p. 37-46.

LEYVAL, C.; TURNAU, K.; HASELWANDTER, K. Effect of heavy metal pollution on mycorrhizal colonization and function: physiological, ecological and applied aspects. Mycorrhiza, Berlin, v. 7, p. 139-153, 1997.

MILLER, R. M.; JASTROW, J. D. The application of V. A. mycorrhizae to ecosystem restoration and reclamation. In: MICHAEL, F. A. (Ed.). Mycorrhizal functioning: an integrative plant-fungal process. London: Chapman and Hall, 1992. p. 438-467.

RASKIN, I.; SMITH, R. D.; SALT, D. E. Phytoremediation of metals: using plants to remove pollutants from the environment. Plant Biotechnology, Sheffield, v. 8, p. 221-226, 1997.

SALT, D. E.; PRINCE, R. C.; PICKERING, I. J.; RASKIN, I. Mechanisms of cadmium mobility and accumulation in Indian mustard. Plant Physiology, Rockville, v. 109, p. $1427-1433,1995$

SALT, D. E.; SMITH, R. D.; RASKIN, I. Phytoremediation. Annual Review of Plant Physiology, Palo Alto, v. 49, p. 643-668, 1998.

SARRUGE, J. R.; HAAG, H. P. Análises químicas em plantas. Piracicaba: Esalq, 1974. 56 p.

SARWAR, M.; KIRKEGAARD, J. A. Biofumigation potential of brassicas. I. Variation in glucosinolate profiles of diverse field-grown brassicas. Plant and Soil, Dordrecht, v. 201, p. 71-89, 1998.

SHETTY, K. G.; HETRICK, B. A. D.; SCHWARB, A. P. Effects of mycorrhizae and fertilizer amendments on zinc tolerance of plants. Environmental Pollution, Oxford, v. 88 , p. $307-314,1995$.

SIQUEIRA, J. O.; SAGGIN-JUNIOR, O. J. The importance of mycorrhizae association in natural lowfertility soils. In: INTERNATIONAL SYMPOSIUM ON ENVIRONMENTAL STRESS, 1., 1992, Belo Horizonte Proceedings... Sete Lagoas: Embrapa-CNPMS/Cymmyt, 1995. p. 239-280.

SIQUEIRA, J. O.; PEREIRA, M. A. M.; SIMÃO, J. B. P.; MOREIRA, F. M. S. Efeito da formononetina (7 Hidroxi, 4" metoxi Isoflavona) na colonização micorrízica e crescimento do milho em solo contendo excesso de metais pesados. Revista Brasileira de Ciência do Solo, Campinas, v. 23, p. 571-577, 1999.

SMITH, S. E.; READ, D. J. Mycorrhiza symbiosis. London: Academic, 1997. 480 p. 
TOMMERUP, I. C. Spore dormancy in vesicular-arbuscular mycorrhizal fungi. Transactions of the British Mycological Society, Cambridge, Inglaterra, v. 81, p. 381-387, 1983.

VALSECCHI, G.; GIGLIOTI, C.; FARINI, A. Microbial biomass, activity, and organic matter accumulation in soils contaminated with heavy metals. Biology and Fertility of Soils, Berlin, v. 20, p. 253-259, 1995

VANGRONSVELD, J.; CUNNINGHAM, S. D. Metalcontaminated soils: in situ inactivation and phytorestoration. Berlin: Springer, 1998. 265 p.
VIDAL, M. T.; ÁZCON-AGUILAR, C.; BAREA, J. M. Effect of heavy metals $(\mathrm{Zn}, \mathrm{Cd}$ and $\mathrm{Cu}$ ) on arbuscular mycorrhiza formation. In: EUROPEAN SYMPOSIUM ON MYCORRHIZAS, 4., 1994, Granada. Proceedings... Granada: European Commission, 1996. p. $487-490$

ZAROSKY, R. J.; BURAU, R. G. A rapid nitric perchloric acid digestion method for multi element tissue analysis Communications in Soil Science and Plant Analysis, New York, v. 8, p. 425-436, 1977. 